heat of the earth still plays an important if not controlling part in all terrestrial phenomena. ..." This idea is based on an earlier communication ${ }^{6}$ whose conclusions are invalidated by his erroneous definition of temperature and by his erroneous assumption that a body placed in a stream of radiant energy has its temperature raised by an amount proportional to the quantity of radiant energy falling upon it in a unit of time.

It can readily be shown that the heat received by conduction from the earth is insignificant in comparison with that received from the sun, as was long ago done by Lord Kelvin. The quantity of heat reaching the earth's surface per minute through each sq. $\mathrm{cm}$. equals the conductivity of the rock multiplied by the temperature gradient multiplied by 60 seconds. If we take the conductivity of rock at 0.005 and the temperature gradient at $0.00032^{\circ} \mathrm{C}$. per $\mathrm{cm}$. (which corresponds to $1^{\circ}$ C. per $31 \mathrm{~m}$. or $1^{\circ} \mathrm{F}$. per 50 feet) we find $9.6 \times 10^{-5}$ for the quantity of heat conducted to the surface per sq. $\mathrm{cm}$. each minute, and since we can take the quantity received from the sun for the same area in the same time as 0.2 calorie, we see that the earth's surface receives from the sun at least 2,000 times as, much heat as from its interior. The latter, therefore, could not have a material effect on the surface temperature or on atmospheric phenomena. Harry Fielding Reid

JoHNS HOPEINS UNIVERSITY,

November 28, 1908

\section{ON MISLEADING STATEMENTS}

SINCE misleading statements occur in the publications of certain writers concerning my participation in, and experimental contributions to the subject of blood-vessel anastomosis and transplantations, in justice to myself and in the interest of investigators in general, it is incumbent upon me to perform the disagreeable task of making a statement once for all, that the facts may be made readily accessible. The task will be made easier if I am permitted to quote rather freely.

Carrel in a paper appearing in the Journal of the American Medical Association, November 14, 1908, LI., p. 1664, says:

' ScIence, December 20, 1908, p. 877.
The transplantation of devitalized arteries has been attempted by Levin and Larkin in New York, but in almost every case thrombosis occurred. However, after the transplantation of a segment of aorta fixed in formalin into the aorta of a dog, excellent circulation was observed. Histologic examination ten days after the transplantation showed that the wall was composed of amorphous tissue in which the elastic framework was seen to be very well preserved. In another case of Levin and Larkin, twenty days after the operation, the wall of the vessel was completely amorphous and surrounded by dense connective tissue. A similar experiment has been performed in $s t$. Louis by Guthrie, who obtained an excellent functional result, but no histologic examination of the vessel has yet been published.

Levin and Larkin, in Proceedings of the Society for Experimental Biology and Medicine, 1907-8, V., p. 110, say:

On January 23, 1908, we transplanted a segment of aorta from a dog hardened in 4 per cent. formalin into the abdominal aorta of another dog. Meanwhile Guthrie reported successful implantation of formaldehyde segments into the carotid of the dog.

The facts regarding the transplantation of formaldehyde-fixed segments are as follows: In the American Journal of Physiology, September 2, 1907, XIX., 482-7, in the paper entitled, "Heterotransplantations of Blood Vessels," I stated:

In this connection it may be mentioned that a segment of aorta from a cat preserved in formaldehyde for about a month, then washed in very dilute ammonia water, partially dehydrated in alcohol and impregnated with vaseline, when similarly transplanted into a dog gave excellent temporary results. On killing the animal with ether and examining the segment, it was found to resemble the artery of the dog in a much greater degree than before being transplanted, being more pliant and having a flesh color, the latter due, no doubt, largely to the presence of blood that got into or between the coats from the outside. The union of the intimas was excellent, and they both had the characteristic glistening appearance. My thanks are due Dr. Bartlett for assistance with this operation. A series of operations are being made with the view of determining the permanent results of similarly prepared and transplanted blood vessels.

My records show that this experiment was performed June 20, 1907. In ScIEnce, N. S., 
March 20, 1908, XXVII., p. 473, is reported the successful transplantation of a formaldehyde-fixed segment of blood vessel into a dog. Since the work had been announced in 1907 in the article referred to above, I did not consider it necessary or even of interest to state the date of the successful operation. Since this appears to have been a mistake on my part, I desire for the benefit of those interested to here record it. My record shows that the operation reported was performed January 22, 1908. On February 12, 1908, the neck was opened and the segment directly examined. On February 29, 1908, the animal was demonstrated before the St. Louis Medical Society. ${ }^{1}$ The manuscript of the note in ScrENCE was mailed to the editor February 17, 1908.

Levin and Larkin in Proceedings of the Society for Experimental Biology and Medicine, 1907-8, V., 109, also say:

Carrel demonstrated that it is not only possible to unite the two ends of a severed artery by a suture but also to interpose between the cut ends of it a segment of an artery of another animal and perform a double anastomosis. The success of the operation is due to the fine technique elaborated by Carrel. ${ }^{2}$

The following quotations from a paper entitled, "Uniterminal and Biterminal Venous Transplantations," by Carrel and Guthrie (from the Hull Physiological Laboratory, University of Chicago), Surgery, Gynecology and Obstetrics, March, 1906, II., pp. 266-77, will furnish those interested food for thought:

The transplantation of veins is a new operation, and has been largely developed in this laboratory. Therefore its history is short.

In 1902, however, Carrel had shown that arteriovenous anastomoses were possible, and considered that all the transplantation of veins were feasible. Our present results have entirely confirmed this opinion.

In 1905 we began experimenting in this laboratory $^{3}$ with the view, among others, of making a

${ }^{1}$ Interstate Medical Journal, XV., No. 6.

${ }^{2}$ The italics used in the above quotations are my own.

${ }^{3}$ The work in this labcratory has been conjointly performed. complete study of the transplantation of veins. Several series of experiments were undertaken in order to study the results of the uniterminal and biterminal venous transplantations, and they were thoroughly successful. At this point we wish to thank Dr. Stewart for his interest in this work and his valuable suggestions, which have contributed in no small degree to its success.

In order, therefore, to successfully transplant veins on to the arterial system, it was necessary to have a technique permitting the union of the vessels without hemorrhage or thrombosis. Besides, positive results must be constant, for a method is not satisfactory otherwise. In the first experiments (1902), the technique employed did not always yield good results. Thrombosis often occurred. This was due mainly to the fact that the delicacy of the endothelium of the vessels was not appreciated. This led to a realization of the fact that ordinary surgical methods are inadequate. The methods, for instance, which give splendid results in abdominal surgery are much too rough for use in vascular surgery. The surgery of the blood vessels is a new and special field, and the operative handling must be delicately adjusted and adapted to the nature and the reactions of the tissues.

According to these considerations, our technique was improved by degrees. The threads and the needles were the finest and the strongest obtain. able. The threads were sterilized in vaseline, and applied when heavily coated with the same. The vessels were handled very gently, and the endothelium was protected from drying by isotonic sodium chloride solution or by sterilized vaseline. No dangerous metallic forceps were used. The greatest care was exercised to obtain accurate and smooth approximation of the endothelium of the vessels. Finally, we developed a technique which is equally well adapted for arterio-arterial, venovenous, or arterio-venous anastomoses, and which yields uniformly successful results.

This new technique has been used since August, 1905. Numerous arterio-venous anastomoses and transplantations of veins have been successfully performed. Union of the walls of an artery and a vein to each other may be made without the subsequent occurrence of hemorrhage or stenosis.

Modesty should prevent, but I am unable to refrain from remarking in passing that it is a singular fact that up till the time Carrel and I engaged in the work together he reported that his experiments did not always 
yield good results, and that our results almost from the beginning of our work together were excellent! Indeed, so far as I have been able to determine, Carrel working first with Berard, then with Morel in France, and later by himself in Dr. Carl Beck's laboratory in Chicago, claims only one permanently successful result. ${ }^{4}$ This was an arterio-venous anastomosis made with Morel between the jugular vein and carotid artery of a dog. The animal was under observation but a short time and ultimately was lost, so no direct examination of the result was made. But in all probability it would have remained good. He attributed his earlier unsuccessful results to "poor asepsis," but since I have observed that moderate infection is of slight importance as regards the result which such blood vessels as he used are united by the methods perfected by him and myself, this, it would seem, is not the full explanation. As to priority, it gives me great pleasure to express my high regard for Dr. Carrel's persistence in the face of a long series of unsuccessful operations and I desire to in no way endeavor to attach any of the credit he deserves for this devotion.

Many experimenters have endeavored to sew together openings in blood vessels and to unite them end-to-end. To verify this statement one need only to refer to a modern work on surgery, e. g., "American Text-book of Surgery," 1903, p. 292. Murphy, himself the author of a successful method of end-to-end anastomosis-a method used successfully on man-gives a short but valuable summary of the literature, ${ }^{5}$ beginning with the successful suture of a longitudinal incision in an artery in 1762 by Broca.

The dubious distinction of priority which it would appear is the goal sought by some of our contemporaries, presents slight attraction to the sincere investigator whose reward largely is the consciousness that his labors may in the end add a line to the encyclopedia of science.

${ }^{4}$ See Surgery, Gynecology and Obstetrics, March, 1906, II., p. 269.

5 "Resection of Arteries and Veins Injured in Continuity-End-to-End Suture," Medical Record, January 16, 1897.
In addition to the references given above a list of the more important papers published conjointly by Carrel and the writer is appended:

"Functions of a Transplanted Kidney," ScIENCE, N. S., October 13, 1905, XXII., p. 473.

"Extirpation and Replantation of the Thyroid Gland with Reversal of the Circulation," ScIence, N. S., October 27, 1905, XXII., p. 535.

"Transplantation Biterminale Complete d'un Segment de Veine sur une Artere," Comptes Rendus Heb. des séances de la Société de Biologie, Novembre 17, 1905, LIX., pp. 412-13.

"Successful Transplantation of both Kidneys from a Dog into a Bitch, with Removal of both Normal Kidneys from the Latter," ScIEnce, N. S., March 9, 1906, XXIII., pp. 394-5.

"Results of a Replantation of the Thigh," ScIENCE, N. S., March 9, 1906, XXIII., pp. 393-4.

"A New Method for the Homoplastic Transplantation of the Ovary," Scrence, N. S., April 13, 1906, XXIII., p. 591. C. C. GuthrIE

Department of Physiologr, WASHINGTON UNIVERSITY, St. LouIs

\section{WILLIAM KEITH BROOKS}

To the Editor of ScIEnce: Allow me to call attention to several errois that appeared in my sketch of William Keith Brooks, in ScIence, for the fourth of December, 1908. On page 777 Brooks's college education is ascribed to his own exertions, but in fact not only did his parents put no obstacles in his way but his father sent him to Hobart College and later to Williams College. It was only his subsequent, post-graduate training, that required Brooks's own labors. Moreover, it is doubtful if his experience in his father's counting-office was not after he had finished his college education. Again on page 778 Hobart College is confounded with the De Vaux College, a school for boys near Niagara Falls. It seems that Brooks was a student at Hobart, entering in 1866, and leaving at the end of his sophomore year to go to Williams College, where he graduated in 1870. Subsequently he taught, as one of the masters, at De Vaux College, from 1870 to 1873 . On the same page Tyron should read Tryon and H. Tuttle, Albert H. Tuttle.

E. A. ANDREws 